\title{
Present treatment of rectal adenocarcinoma
}

\author{
J. P. Gerard, O. Thomas, C. Ortholan
}

\section{Improvement since 30 years. Surgery is the main treatment}

Surgery is the basic treatment of rectal adenocarcinoma. Within the past 30 years post operative death has decreased from $10 \%$ to less than $4 \%$. Permanent colostomy went down from $80 \%$ to less than $40 \%$. The standard surgical approach is now sharp dissection of the mesorectum under direct vision called "TME" (Total Mesorectal Excision) surgery". The 5 year overall has increased from 45 to $60 \%$. Rectal adenocarcinoma that was considered as a radioresistant tumor is now treated with preoperative External Beam Radiation Therapy (EBRT) in most of cases ${ }^{2}$.

\section{Perirectal and hypogastric nodal metastasis.}

The Japanese work shows that the rate of perirectal Lymph Nodes (LN) varies from $13 \%$ in pT1 lesions to $64 \%$ in pT3. There is no hypogastric $\mathrm{LN}$ metastases in $\mathrm{pT} 1-2$ and $11 \%$ in pT3 tumors. When hypogastric $L N$ are involved the survival at 5 years is close to zero percent ${ }^{3}$. There is at present time no reliable imaging technique to diagnose before surgery the $\mathrm{N}$ stage. May be MRI with specific contrast magnetic product will be relevant. Endorectal sonography is reliable to distinguish between T2 and T34. The definition of T4 is still rather subjective.

\section{Circumferential Rectal Margin (CMR)}

Since the work of Quirke ${ }^{5}$ and the Dutch Colorectal group TME trial ${ }^{6}$, the CRM appears as an important end point to predict for local failure and distant metastases when it is involved on the pathological specimen. The definition of CRM $\mathrm{R} 1$ varies from 0 to $2 \mathrm{~mm}$ according institutions. The use of MRI appears interesting to identify before treatment patient at risk of CRM R $1^{7}$.

\begin{abstract}
Adenocarcinoma is a moderately radiosensitive disease
Radiotherapy alone in a preoperative schedule can provide complete sterilisation of T2-3 rectal adenocarcinoma in 5 to $15 \%$. When used alone with very high dose thanks to endocavitary irradiation (contact X-Ray+/-iridium brachytherapy) control of $90 \%$ of T1NO lesions is possible. In inoperable patients a combination of EBRT (small posterior pelvic volume) and endocavitary irradiation is able to control 60 to $80 \%$ of T2-3 lesions and most of all sterilize subclinical perirectal lymph nodes 8 , 9 .
\end{abstract}

\section{Recent improvements in surgery}

All the surgeons agree that the standard technique of surgery in "TME surgery" aiming at the sharp dissection of the rectum to avoid as much as possible a CRM R1. In the same time great care is taken not to section the hypograstric and presacral nerve which are of importance for urinary bladder and sexual function. Sphincter preservation is possible in many cases with colorectal very low anastomoses. A margin of $2 \mathrm{~cm}$ below the gross tumor is accepted by most surgeons. Reservoir may be useful during the first year after surgery to improve anal function. Intersphincteric dissection can further increase sphincter preservation but often leads to poor anal function. Local excision for T1 lesion or after preoperative EBRT for T2 or small T3 may gain interest in the near future.

\section{Can we improve over surgery alone?}

Many end points are relevant. The major one is overall survival but it takes many years to analyse. Disease free survival is a good indicator of overall survival. Local control is important because a high rate of local failure decreases the chance of cure and is responsible for very distressful symptom. Sphincter preservation is for all the patients a very serious concern. Improving sphincter preservation must not be at the price of an increase in local relapse or poor anorectal function and deteriorated quality of life mainly social life. Toxicity of adjuvant treatment is important. Care must be taken not to increase operative death or poor anorectal function.

\section{From postoperative radio(chemo)therapy to preoperative} radiotherapy

In 1990 American clinical Trials demonstrated that despite significant toxicity postoperative radiotherapy (45-50.4 Gy) 
and concurrent continuous infusion of Fluorouracil with folinic acid was able to improve local control and overall survival. Since these works three trials (Uppsala, NSABP 03 and the German CAO/ARO/AIO) have proven that preoperative radiotherapy or radiochemotherapy is less toxic and give better local control than a postoperative schedule ${ }^{10,11,12}$. It may also increase the chance of sphincter preservation if there is an interval of 4 weeks or more after EBRT. The Swedish Trial has proven that preoperative EBRT with a short schedule (25 Gy/5 day) can increase local control and overall survival ${ }^{13}$. But all these trials were done without standard TME surgery. The merit of the DCRCG TME trial is to demonstrate than even with TME preoperative EBRT (25 Gy/5 days) improves local control but not survival. At 5 years the local failure rate is $11.3 \%$ with TME alone and $5.8 \%$ with preoperative EBRT $(p=0.001)$.

\section{The role of concurrent and adjuvant chemotherapy.}

Two randomised Italian and Dutch Trials with 5FU and folinic acid adjuvant chemotherapy has failed to demonstrate a survival benefit. It is possible that the adjuvant benefit from 5FU is different between Colon and Rectum cancer ${ }^{14}$. Two randomised Trials (EORTC 22921 and FFCD 92 03) initiated in 1993 have been closed in 2003. Both Trials randomised in T3-4 MO rectal cancer preoperative EBRT (45Gy/5 weeks) alone vs the same EBRT and concurrent chemotherapy (5FU+Folinic acid). Preliminary results of these two trials show an increase in early toxicity with the combined treatment but no increase in postoperative death ${ }^{15}$. The FFCD 92 03 trials shows a significant increase in complete pathological response (sterilisation) from 3 to $10 \%$ but no difference in sphincter preservation (51\%). In 2004 taking into consideration these data preoperative radiotherapy alone should be considered standard for T3 and resectable T4 (and low T2) tumors. The best regimen between $25 \mathrm{~Gy} / 5$ days and 45 $\mathrm{Gy} / 5$ weeks is not known although many radiation oncologists feel that $45 \mathrm{~Gy}$ is less toxic. The benefit of concurrent chemotherapy is not yet proven.

\section{Future improvements}

Sphincter preservation is an end point of great clinical reference. Two Lyon randomised Trials tend to show that a long interval of 4 weeks or more after EBRT can increase sphincter preservation $^{16}$ and that a dose escalation using contact $X$-ray increases significantly sphincter preservation with the possibility in some patients to perform only a trans anal excision. On the opposite a Polish Trial failed to demonstrate a benefit of $50 \mathrm{~Gy} / 5$ weeks + chemo long interval vs $25 \mathrm{~Gy} / 5$ days immediate surgery.

Many phase I and II trials show encouraging results in term of tumor response and operative regimen sterilisation using concurrent EBRT (45 Gy-50 Gy/5-6 weeks) and Oxaliplatin, Capecitabine, Irinotecan and other biomodulators. The Xelox combination (Oxaliplatin and Capecitabin) appears promising to many authors ${ }^{17,18}$. Future phase III trials will try to show an improvement with preoperative concurrent chemoradiation. Local control which is close to $5 \%$ in the DLRCG trial is not any more the major endpoint. Adjuvant chemotherapy will in a near future become a major question regarding liver metastases and overall survival.

\section{References}

1. Heald RJ, Moran BJ, Ryall RD et al. Rectal cancer: the Basingstoke experience of total mesorectal excision 1978-1997. Arch Surg 1998; 133:894-9.

2. Medical Research Council Rectal Cancer Working Party: Randomised trial of surgery alone vs. radiotherapy followed by surgery for potentially operable locally advanced rectal Cancer. Lancet 1996; 348:1605-10.

3. Hida J, Yasutomi M, Fujimoto K, Maruyama T, Okuno K, Shindo K. Does lateral lymph node dissection improve survival in rectal carcinoma? Examination of node metastases by the clearing method. J Am Coll Surg 1997; 184:475-80.

4. García-Aguilar J, Pollack J, Lee SH, Hernández de Anda E, Mellgren A, Wong WD, Finne CO, Rothenberger DA, Madoff RD. Acuracy of endorectal ultrasonography in preoperative staging of rectal tumors. Dis Colon Rectum 2002; 45:10-5.

5. Quirke $P$, Durdey $P$, Dixon MF et al. Local recurrence of rectal adenocarcinoma due to inadequate surgical resection: Histopathological study of lateral tumour spread and surgical excision. Lancet 1986; 2:996-9.

6. Kapiteinjn E, Marijnen CAM, Nagtegaal ID, Putter H, Steup WH, Wiggers T, Rutten HJ, Pahlman L, Glimelius B, van Krieken JH, Leer JW, van de Velde CJ. Dutch Colorectal Cancer Group. Preoperative radiotherapy combined with total mesorectal excision for resecable rectal cancer. N Engl J Med 2001; 345:63846.

7. Beets-Tan RG, Beets GL, Vliegen RF, Kessels AG, Van Boven H, von Meyerfeldt MF, Baeten CG, van Engelshoven JM. Accuracy of magnetic resonance imaging in prediction of tumour-free resection margin in rectal cancer surgery. Lancet 2001; 17:497504.

8. Gerard JP, Chapet $O$, Ramaioli A. Long term control of T2-3 rectal adenocarcinoma with radiotherapy alone. Int J Radiat Oncol Biol Phys 2002; 54:142-9.

9. Gerard JP, Ayzac L, Coquard R et al. Endocavotary irradiation for early rectal carcinoma T1 (T2): A series of 101 patients treated with the Papillon's technique. Int J Radiat Oncol Biol Phys 1996; 36:775-83.

10. Frykholm GJ, Glimelius B, Pahlman L. Preoperative or postoperative irradiation in adenocarcinoma of the rectum: Final treatment results of a randomised trial and an evaluation of late secondary effect. Dis Colon Rectum 1993; 36:564-72.

11. Fisher B, Wolmark $\mathrm{N}$, Rockette $\mathrm{H}$ et al. Postoperative adjuvant chemotherapy or adjuvant radiation therapy for rectal cancer: Results from NSABP R-01. Nat Cancer Inst 1988; 80:21-9.

12. Sauer R. Adjuvant versus neoadjuvant combined modality treatment for locally advanced rectal cancer: first results of the German rectal cancer study (CAO/ARO/AIO-94). Int J Radiat Oncol Biol Phys 2003; 57(suppl 2):124-5s.

13. Swedish Rectal Cancer Trial: Improved survival with preoperative radiotherapy in resectable rectal cancer. $N$ Engl J Med 1997; 336:980-7.

14. The AXIS collaborators. Randomised clinical trial of adjuvant radiotherapy and 5-fluorouracil infusion in colorectal cancer (AXIX). BJC 2003; 90:1200-12.

15. Bosset JF, Calais G, Daban A, Berger C, Radosevic-Jelic L, Maingon $P$, Bardet $E$, Pierart $M$, Briffaux A, EORTC Radiotherapy Group. Preoperative chemoradiotherapy versus preoperative radiotherapy in rectal cancer patients: assessment of acute 


\section{J. P. Gerard y cols.}

toxicity and treatment compliance. Report of the 22921 randomised trial conducted by the EORTC Radiotherapy Group. Eur J Cancer 2004; 40:219-24.

16. Francois Y, Nemoz JC, Baulieux J, Vignal J, Grandjean JP, Partensky C, Souquet JC, Adelaine P, Gerard JP. Influence of the interval between preoperative radiation therapy and surgery on downstaging and on the rate of sphincter-sparing surgery for rectal cancer: the Lyon R90-01 Randomised Trial. J Clin Oncol $1999 ;$ 17:2396-402.

17. Gerard JP, Chapet O, Nemoz C, Romestaing P, Mornex F, Co- quard R, Bardet N, Atlan D, Adeleine P, Freyer G. Preoperative concurrent chemoradiotherapy in locally advanced rectal cancer with high-dose radiation and Oxaliplatin-Containing regimen: The Lyon R0-04 Phase II Trial. J Clin Oncol 2003; 21:1119-24.

18. Freyer G, Bossard N, Romestaing P, Mornex F, Chapet O, Trillet-Lenoir V, Gerard JP. Addition of Oxaliplatin to continuous Fluorouracil, L-Folinic acid and concomitant radiotherapy in rectal cancer: the Lyon R 97-03 phase I Trial. J Clin Oncol $2001 ; 19: 2433-8$.
Correspondence:

Jean-Pierre Gerard

Centre Antoine Lacassagne

33 Avenue de Valombrose

06189 NICE cedex 2

E-mail: jean-pierre.gerard@cal.nice.fnclcc.fr 